\title{
ПРЕЖДЕВРЕМЕННОЕ ПРЕРЫВАНИЕ ВОСПИТАНИЯ ПРИЕМНЫХ ДЕТЕЙ В ЗАМЕЩАЮЩИХ СЕМЬЯХ: ОБЗОР РОССИЙСКИХ И ЗАРУБЕЖНЫХ ИССЛЕДОВАНИЙ
}

\author{
Л.А. АСЛАМАЗОВА ${ }^{\mathrm{a}, \mathrm{b}}$, Р.Ж. МУХАМЕДРАХИМОВ \\ ${ }^{a}$ ФГБОУ ВО «Адыгейский государственный университет», 385000, Республика Адыгея, г. Майкоп, \\ ул. Первомайская, Ә. 208 \\ ${ }^{b}$ ФГБОУ ВО «Санкт-Петербургский государственный университет», 199034, Россия, Санкт- \\ Петербург, Университетская набережная, д. 7-9
}

\section{Disruption of Substitute Care: A Review of Russian and Foreign Studies}

\author{
L.A. Aslamazova ${ }^{\mathrm{a}, \mathrm{b}}$, R.J. Muhamedrahimov ${ }^{\mathrm{b}}$, K.G. Tumanyan ${ }^{\mathrm{b}}$ \\ ${ }^{a}$ Adyghe State University, Address: St. Pervomayskaya, 208, Maykop, Adygea Republic, 385000, Russian Federation \\ ${ }^{b}$ Saint Petersburg State University, 7/9 Universitetskaya emb., Saint Petersburg, 199034, Russian Federation
}

\begin{abstract}
Резюме
Проявления замещающей семейной заботы о детях-сиротах и детях, оставшихся без попечения родителей, сопровождаются случаями преждевременного прерывания воспитания приемных детей, число которых увеличивается с усилением интенсивности устройства их в семьи. Изучение причин преждевременного прерывания (отказа) от продолжения воспитания приемного ребенка со стороны замещающих родителей осуществляется в отечественных и зарубежных исследованиях, многочисленные результаты которых требуют проведения информационно-аналитического обзора. Цель работы состоит в анализе и обобщении результатов психологических исследований отказа от продолжения воспитания приемного ребенка. Результаты свидетельствуют о том, что основные направления исследований связаны с
\end{abstract}

\begin{abstract}
Substitute family care for orphaned children and children left without parental care is accompanied by cases of its disruption, the number of which increases with the intensity of placement of children in families. Studies of the causes of disruption were conducted in Russia and abroad, and their numerous results require an analytical review. The objective of the current work is to analyze results of psychological studies on disruption of substitute care. The review reveals that the research is focused mostly on characteristics of foster children and substitute families that increase the risk of the refusal to continue substituted upbringing, as well as on the specifics of the relations between a foster child and their relatives.
\end{abstract}


изучением влияющих на отказ от продолжения воспитания особенностей приемных детей, характеристик замещающих родителей и семей, а также особенностей возможного взаимодействия приемного ребенка с биологической семьей. Результаты работы и их обсуждение позволяют сделать выводы, что отказ от проживания приемного ребенка в семье представляет собой сложное явление, на которое оказывают влияние разнообразные факторы, связанные как с особенностями детей, так и с особенностями замещающих родителей, а также с влиянием биологической семьи на процессы, происходящие в замещающей семье. Опыт отказа, переживаемый приемным ребенком и замещающими родителями, имеет множественные негативные психологические последствия для обеих сторон, в том числе в виде переживания чувства утраты, изоляции, обесценивания отношений, психической травматизации. Обеспечение проживания детейсирот и детей, оставшихся без попечения биологических родителей, в стабильных и качественных условиях замещающей семьи предполагает повышение качества подготовки замещающих родителей, а также разработку и внедрение научно обоснованных профилактических программ сопровождения ребенка и замещающей семьи.

Ключевые слова: замещающая семья, приемные дети, факторы отказа от продолжения воспитания, научно обоснованные программы сопровождения.

Асламазова Лилия Артуровна - доцент, кафедра педагогической психологии, факультет педагогики и психологии, Адыгейский государственный университет; докторант, кафедра психического здоровья и раннего сопровождения детей и родителей, факультет психологии, Санкт-Петербургский государственный университет, кандидат психологических наук, доцент. Сфера научных интересов: психическое здоровье детей, взаимодействие ребенка и близкого взрослого, программы вмешательства для замещающих семей, психологическое консультирование детей и родителей.

Контакты: lily.aslamazova@gmail.com

Мухамедрахимов Рифкат Жаудатович - профессор, заведующий кафедрой психического
The discussion emphasizes that the disruption of substitute care is a complex phenomenon associated with characteristics of children and their substitute parents, as well as with the influence of child's relatives on the substitute family. The conclusion highlights the need to improve the quality of training of substitute parents and to implement the evidence-based intervention programs for children and parents in substitute families.

Keywords: substitute family, foster children, factors care disruption, evidencebased intervention programs.

Liliya A. Aslamazova - Associate Professor, Division of Pedagogical Psychology, Department of Pedagogy and Psychology, Adyghe State University; Doctoral Student, Division of Child \& Parent Mental Health and Early Intervention, Department of Psychology, Saint-Petersburg State University, PhD in Psychology, Associate Professor.

Research Area: child mental health, caregiver-child interaction, intervention programs for substitute families, psychological counseling for children and parents. E-mail: lily.aslamazova@gmail.com

Rifkat J. Muhamedrahimov - Professor, Chair of Division of Child \& Parent 
здоровья и раннего сопровождения детей и родителей, факультет психологии, Санкт-Петербургский государственный университет, доктор психологических наук, профессор.

Сфера научных интересов: психическое здоровье детей, взаимодействие и привязанность ребенка и близкого взрослого, раннее вмешательство для детей с особыми потребностями, воспитывающихся в семьях и учреждениях.

Контакты: rjm@list.ru

Туманьян Карина Георгиевна - аспирант, кафедра психического здоровья и раннего сопровождения детей и родителей, факультет психологии, Санкт-Петербургский государственный университет.

Сфера научных интересов: психическое развитие детей раннего возраста, особенности взаимодействия матерей с детьми и формирование привязанности у детей в замещающих семьях, программы раннего вмешательства для замещающих семей.

Контакты: karinatumanyan@gmail.com
Mental Health and Early Intervention, Department of Psychology, Saint-Petersburg State University, DSc in Psychology, Professor.

Research Area: child mental health, caregiver-child interaction and attachment, early intervention for children with special needs in families and institutions.

E-mail: rjm@list.ru

Karina G. Tumanyan - Postgraduate, Division of Child \& Parent Mental Health and Early Intervention, Department of Psychology, Saint-Petersburg State University.

Research Area: early child development, mother-child interaction, attachment in children in foster care, early intervention programs.

E-mail: karinatumanyan@gmail.com

\section{Введение}

Преждевременное прерывание воспитания приемных детей представляет собой глобальную проблему системы замещающей семейной заботы как в России, так и за рубежом. Интенсивное устройство детей-сирот и детей, оставшихся без попечения родителей, на воспитание в семьи неизбежно ведет к увеличению случаев отказов от их проживания в семье. Согласно российским официальным данным, ежегодно отменяется порядка 1\% всех решений о передаче детей на воспитание в семью (Министерство труда и социальной защиты Российской Федерации, 2016). При этом отказы зачастую носят латентный характер, нередко маскируются под переводы приемных детей из одной замещающей семьи в другую, что ведет к неточностям реального представления об их числе (Осипова, 2008). В 60-70\% случаев инициаторами отказов выступают замещающие родители, еще 13-16\% семей распадается в силу ненадлежащего выполнения воспитателями своих обязанностей (Бирюкова и др., 2014; Министерство труда и социальной защиты Российской Федерации, 2016).

В российской литературе преждевременное прерывание воспитания приемных детей приравнивается ко вторичному сиротству (Осипова, 2008; Бирюкова и др., 2014; Цинченко, 2014), являющемуся частью социального сиротства, связанного с отказом родителей от воспитания детей (Осипова, 2008; Заяц, Кизим, 2014). Согласно авторам, корни данного феномена лежат в нестабильности института семьи, деформации семейных ролей и ценностей, включая снижение ответственности и качества выполнения родителями своих функций (Осипова, 2008). Отказ рассматривается не как отдельное событие в жизни приемного ребенка, а как сложный процесс, оказывающий 
значительное влияние на опыт и личную историю ребенка (Khoo, Skoog, 2014; Harkin, Houston, 2016), и приравнивается к психологическому насилию (Рамих, 2018). Возвращенные дети переживают разрыв эмоциональных связей и отношений с приемными родителями, что приводит к активации механизмов психологической защиты (Куфтяк, 2012; Рамих, 2018) и снижению уровня доверия к взрослым, ухудшению контактности (Корзетова, 2016; Леонова, 2018). Без психологической реабилитации и сопровождения ребенка, пережившего психическую травму, дальнейшее размещение в новой семье малоэффективно и имеет высокую вероятность повторения отказа (Цыганова, 2015). В связи с большим числом случаев преждевременного прерывания воспитания приемных детей авторы отмечают уязвимость института замещающей семьи как программы вмешательства и сопровождения детей, оставшихся без попечения родителей (Vanderfaeillie et al., 2018a). При этом отказ от воспитания приемного ребенка имеет последствия для замещающих родителей, которые испытывают смешанные чувства (наряду с облегчением опустошение, разочарование, несостоятельность), переживают травму и нуждаются в психологической помощи (Selwyn et al., 2014; Корзетова, 2016).

Анализ немногочисленных работ отечественных авторов на тему отказов свидетельствует о том, что большинство из них носят выраженный прикладной характер с описанием практики сопровождения замещающих семей (Павлова, 2015; Семенова, 2015; Решетова, 2016; Беспалова, 2019) либо представляют собой краткие сообщения и тезисы (Шулятьева и др., 2016). В то же время вопросы, связанные с отказом от воспитания приемных детей в семье, тщательно изучались в зарубежных исследованиях, которые до настоящего времени в российской психологической литературе не проанализированы. Для полноты представлений о причинах преждевременного прерывания воспитания приемных детей в замещающих семьях, а также для повышения эффективности мер профилактики отказов мы осуществили обзор научных исследований в этой области.

Целью настоящей работы являются выявление, анализ, систематизация и обобщение научной информации, полученной в результате исследований отказа замещающих семей от воспитания приемных детей. Задачи исследования включают обзор научных работ, раскрывающих влияние на отказы особенностей приемного ребенка, замещающих родителей и семьи, а также биологической семьи. Методологическую основу исследования составляет системная теория развития ребенка во взаимодействии с близким взрослым (Stern, 1985) и формирования привязанности (Bowlby, 1969; Ainsworth et al., 1978; Плешкова, Мухамедрахимов, 2008), в рамках которой развитие детей на этапе институционализации до принятия на воспитание в замещающие семьи рассматривается как развитие со значительным нарушением потребности взаимодействия со стабильным и чувствительным близким взрослым (Мухамедрахимов, 1999). Метод исследования - выявление, анализ, обсуждение и обобщение результатов изучения проблемы преждевременного прерывания воспитания приемных детей в замещающих семьях, опубликованных в научных работах российских и зарубежных авторов. 


\section{Результаты}

\section{Преждевременное прерывание воспитания в связи с особенностями приемных детей}

Согласно данным, полученным по результатам опроса родителей в российских замещающих семьях, причинами отказа от продолжения воспитания приемных детей могут быть комплексные проблемы развития, поведения, здоровья, неблагоприятный внешний вид воспитанника, а также негативное влияние приемного ребенка на биологических детей (Семья и др., 2009). В качестве дополнительных факторов риска рассматриваются переживание приемными детьми опыта возвратов, наличие у них сиблингов, совместное или раздельное размещение братьев и сестер в замещающих семьях (Махнач, 2016). Среди поводов для отказа семей от продолжения воспитания приемных детей отечественные авторы выделяют причины, связанные с поведенческими и эмоциональными нарушениями (Осипова, 2008; Семья и др., 2009; Ремизова, 2014; Фещенко, 2015; Корзетова, 2016; Махнач, 2016; Леонова, 2017; Беспалова, 2019), что может быть связано с опытом травматизации, пренебрежения и насилия как в родной семье (Thomas, 2005; Moyers et al., 2006), так и в учреждении (Muhamedrahimov et al., 2014).

Результаты крупных исследований, проведенных зарубежными авторами, свидетельствуют о множественности причин, связанных с особенностями приемных детей, приводящих к преждевременному прерыванию их воспитания в замещающей семье. Так, масштабный анализ показателей стабильности размещения детей в замещающих семьях США (23 760 детей и 66585 случаев размещения) показал, что на преждевременное прерывание воспитания приемных детей в семьях влияют поведенческие трудности, делинквентность, психические проблемы и когнитивные нарушения, число предыдущих размещений (чем больше, тем выше риск возврата), отсутствие сиблингов у воспитанников (Font, Sattler, 2018). Авторы исследования выявили, что семьи чаще отказывались от продолжения воспитания мальчиков и детей из афроамериканских биологических семей. Изучение исходов размещения детей (14 171 ребенок в возрасте от рождения до 17 лет) в семьях неродственной опеки в Германии позволило определить, что факторами риска возвратов являются мужской пол воспитанников, старший возраст помещения в семью (от 6 до 15 лет), наличие опыта проживания в других замещающих семьях, а также антисоциальное поведение, ставшее причиной предыдущего возврата (Santen, 2015). В серии исследований, посвященных изучению распространенности возвратов и связанных с ними факторов в Нидерландах и Бельгии, было проанализировано 580 случаев долгосрочного семейного размещения приемных детей, 169 из которых окончились возвратом в течение шести лет после принятия их в семьи. Авторы отмечают, что наибольший вклад в вероятность отказа от проживания ребенка в семье вносят поведенческие трудности у воспитанников, их принадлежность к группе детей старшего возраста, отвержение предлагаемой семьей заботы и наличие опыта сексуального насилия в прошлом (Vanderfaeillie et al., 2018a; Vanderfaeillie et al., 2018b). 
Исследование восприятия замещающими родителями вторичных отказов, проведенное в Канаде с помощью опроса на выборке из 63 человек (50 семей), показало, что в качестве главных причин окончания воспитания приемного ребенка в семье родители выделяют его неспособность адаптироваться к условиям семейной жизни; трудности в том, чтобы справиться с его поведением; проявление ребенком действий, угрожающих семье, и наличие у него сложных медицинских проблем (Brown, Bednar, 2006). Изучение факторов, способствующих развитию ситуации возврата, проведенное в ЮАР с помощью полуструктурированного интервью переживших возврат подростков и их бывших замещающих родителей, показало, что к отказам приводят: возраст ребенка на момент поступления в семью (чем старше, тем выше риск возврата), деструктивное поведение воспитанника, включая злоупотребление психоактивными веществами, вовлеченность в культы и секты, а также его неподобающее сексуальное поведение (Mnisi, Botha, 2016).

Обобщение результатов этих и других зарубежных исследований позволяет выделить среди причин преждевременного прерывания воспитания в замещающей семье такие связанные с особенностями приемных детей факторы, как экстернальное и антисоциальное поведение (Farmer et al., 2004; Sallnas et al., 2004; Sinclair et al., 2005; Oosterman et al., 2007; Selwyn et al., 2014; Santen, 2015; Harkin, Houston, 2016); неподобающее сексуальное поведение, в том числе связанное с опытом сексуального насилия (Vanderfaeillie et al., 2018a; Vanderfaeillie et al., 2018b); деструктивное поведение, включая злоупотребление психоактивными веществами, вовлеченность в культы и секты (Mnisi, Botha, 2016); неспособность адаптироваться к условиям жизни в семье, неуправляемое и угрожающее семье поведение (Brown, Bednar, 2006). В качестве предикторов отказов авторы выделяют старший возраст принимаемого на воспитание ребенка (Farmer et al., 2004; Sinclair et al., 2005; Selwyn et al., 2014; Santen, 2015; Mnisi, Botha, 2016; Vanderfaeillie et al., 2018a; Vanderfaeillie et al., 2018b); его сложные медицинские потребности (Brown, Bednar, 2006); проживание в биологической семье до времени помещения в систему альтернативной заботы (Farmer et al., 2004); наличие эмоциональных (Egelund, Vitus, 2009) и психических проблем (злость, агрессия, проявление насилия в отношении замещающих родителей и членов семьи, низкая самооценка) (Sallnas et al., 2004; Stanley et al., 2005; Selwyn et al., 2014); нарушение способности устанавливать новые взаимоотношения и формировать привязанность к замещающим родителям (Sinclair et al., 2005; Coman, Devaney, 2011), ожидание приемным ребенком окончания срока размещения в семье, стремление сохранить свой негативный образ в глазах замещающих родителей, опыт эмоционального насилия (Sinclair et al., 2005); отвержение предлагаемой семьей заботы (Vanderfaeillie, Goemans et al., 2018; Vanderfaeillie, Van Holen et al., 2018).

Отдельно выделяется нестабильность размещения ребенка в системе замещающей заботы, приводящая к частой смене семей (от двух и более) (Selwyn et al., 2014), что резко уменьшает положительные результаты развития и не позволяет ребенку чувствовать себя любимым, полноценно раскрывать свой потенциал (Baginsky et al., 2017). Одновременно с данными о том, что замещающие 
родители чаще отказываются от продолжения воспитания мальчиков младшего и среднего подросткового возраста, а также от девочек - старших подростков (Леонова, 2017), показано, что пол и этническая принадлежность ребенка не являются факторами риска отказа (исследование проведено с участием 70 семей-усыновителей из Великобритании с помощью метода интервью) (Selwyn et al., 2014).

\section{Преждевременное прерывание воспитания в связи с особенностями замещающих родителей и семьи}

Среди факторов отказа от продолжения воспитания приемных детей, связанных с особенностями замещающих родителей, выделяют низкий уровень готовности к приему ребенка (Осипова, 2008; Лёвушкин, Данилова, 2014), недостаточность знаний о потребностях детей и понимания процесса замещающей заботы (Khoo, Skoog, 2014), отсутствие умений по управлению трудным поведением воспитанников, что приводит к нарастанию стресса, раздражению, повышению конфликтности, применению физического и эмоционального насилия, снижению доверия и неудачам в налаживании жизни семьи с приемным ребенком (Brown, Bednar, 2006; Maaskant, 2016; Mnisi, Botha, 2016; Лаврентьева, 2017). Вероятность отказа повышается при сложностях взаимодействия замещающих родителей с органами опеки и социальными службами (Brown, Bednar, 2006; Khoo, Skoog, 2014), биологическими родственниками приемного ребенка (Vanderfaeillie et al., 2018a), при чувствительности к мнению окружающих и поиске внешних причин несостоятельности и, как следствие, нарастании эмоционального истощения и выгорания воспитателей (Лаврентьева, 2017). К негативным особенностям замещающей семьи относят дисфункциональность семейной структуры (Шулятьева и др., 2016), неэффективность внутрисемейной коммуникации, наличие в семье агрессии и истории психической травматизации, неумение конструктивно решать проблемы и управлять ресурсами, в том числе материальными (Махнач и др., 2015; Махнач, 2016).

Согласно данным литературы, риск отказа от продолжения воспитания приемного ребенка повышается при таких личностных характеристиках замещающих родителей, как склонность к аддикциям, агрессивность, низкий уровень жизнестойкости, наличие сексуальных проблем, психопатологических черт (у родителя или члена семьи) (Махнач, 2016); жесткость установок в отношении себя и семьи, избегание ответственности, незрелость (Шулятьева и др., 2016). Решение об отказе может наблюдаться при непринятии родителем физического облика и поведения воспитанника, нарушении ожиданий (в отношении ребенка, самого факта приема, возможностей решения с его помощью семейных проблем) и разочаровании в принятом ребенке, при обвинительной позиции родителя (Шулятьева и др., 2016; Лаврентьева, 2017). Среди фундаментальных факторов, приводящих в последующем к отказу семьи от сохранения ребенка, выделяют общую неустойчивость мотивации приема, обуславливающую необдуманность решений, преобладание стремления получить материальную выгоду, снижение альтруистической настроенности (Лёвушкин, Данилова, 2014; Махнач, 2016; Шулятьева и др., 2016). 


\section{Преждевременное прерывание воспитания в связи с влиянием биологической семьи на жизнь приемного ребенка}

Большинство приемных детей приходят в замещающую семью, имея не только воспоминания о своей биологической семье, но и время от времени поддерживаемые с ней связи. В работах отечественных и зарубежных авторов сохранение связи с биологическими родственниками рассматривается как фактор риска отказа от продолжения воспитания, особенно если кровные родители вмешиваются в жизнь замещающей семьи (Moyers et al., 2006; Осипова, 2008; Mnisi, Botha, 2016). Повторное выстраивание контакта с родственниками с воспроизведением дезадаптивной модели взаимодействия оказывает на приемных детей отрицательное воздействие (Thomas, 2005; Moyers et al., 2006), при этом поддержание связи с биологической семьей зачастую имеет для них жизненно важное значение (Sinclair et al., 2005).

Изучение ответов замещающих родителей, полученных с помощью полуструктурированного интервью и раскрывающих особенности восприятия ими поддержки, необходимой в процессе воспитания приемных детей, проведенное в Новой Зеландии, показало, что контакт приемных детей с биологической семьей оказывает негативное влияние на замещающих родителей (Murray et al., 2011). Наличие такого контакта может представлять собой серьезный стрессовый фактор, вызванный необходимостью бороться с трудным поведением воспитанников после родственных визитов, нередкими случаями жестокого обращения со стороны кровных родителей во время взаимодействия либо переживаниями детей в связи с непосещением их близкими или отказом контактировать с ними. Вместе с тем в научной литературе представлены исследования, которые не подтверждают наличия значимой связи между сохранением контакта приемного ребенка с его биологической семьей и отказом замещающих родителей от продолжения воспитания (Sinclair et al., 2005; Oosterman et al., 2007). В ряде работ показано, что взаимодействие между замещающими и биологическими родителями может рассматриваться как защитный фактор, способный предотвратить преждевременные возвраты и улучшающий интеграцию ребенка в приемную семью (Oosterman et al., 2007; Coman, Devaney, 2011; Harkin, Houston, 2016).

\section{Обсуждение}

В настоящей статье проведен обзор исследований преждевременного прерывания (отказа) от продолжения воспитания приемного ребенка со стороны замещающих родителей. Результаты свидетельствуют о том, что основные направления исследований в этой области связаны с изучением влияющих на отказ особенностей приемных детей, характеристик замещающих родителей и семей, а также особенностей возможного взаимодействия приемного ребенка с биологической семьей. В целом представленная информация остро высвечивает проблему сохранения детей-сирот и детей, оставшихся без попечения 
родителей, в замещающих семьях, их благополучия в системе замещающей заботы (Williams-Mbengue, 2016).

Отмечаемые у приемных детей поведенческие и эмоциональные трудности делают их пребывание в замещающих семьях хрупким и неустойчивым и тем самым повышают риск преждевременного прерывания воспитания (Leve et al., 2012; Lopez-Brock, Morales, 2016). Вместе с тем негативная симптоматика, наблюдаемая у подавляющего большинства детей-сирот, помещаемых на воспитание в семьи, обусловлена наличием опыта проживания в условиях депривации и отсутствием взаимодействия со стабильным и чувствительным заботящимся взрослым, что оказывает критическое влияние на самые разные области детского развития, включая когнитивное и социально-эмоциональное, а также на формирование отношений привязанности с близким человеком (Vorria et al., 2003; Плешкова, Мухамедрахимов, 2008; Rutter et al., 2009; Nelson et al., 2014).

Большая часть представленных в данной работе исследований направлена на изучение причин, влияющих на преждевременное прерывание воспитания приемных детей в замещающих семьях, и посвящена изучению характеристик приемных детей. В соответствии с данными литературы (Andersson, 2001) значительно меньше работ адресовано изучению влияния на прерывание воспитания приемных детей особенностей замещающих родителей. По результатам анализа литературы, отказ от продолжения воспитания приемного ребенка может быть обусловлен недостаточной готовностью замещающих родителей к долговременному воспитанию ребенка в семье, особенностями их мотивации и характеристик личности. Полученные нами данные соотносятся с информацией о существенном влиянии особенностей замещающих родителей (Selwyn et al., 2014; Корзетова, 2016) и имеющегося у них опыта, качества родительской заботы, а также наличия поддержки, в том числе и от неформальных источников (семья, друзья, соседи), на стабильность размещения приемных детей в замещающей семье (Crum, 2010; Konijn et al., 2019; Richardson et al., 2018; Leathers et al., 2019).

Полученные в результате изучения литературы данные о влиянии биологических родителей на жизнь приемного ребенка в замещающей семье отличаются противоречивостью, так как в одних работах подчеркивается негативный эффект от поддержания контактов с кровными родственниками, тогда как в других - позитивный. Данные исследований свидетельствуют о том, что контакты с биологической семьей могут как пагубно, так и благотворно влиять на психосоциальное функционирование приемного ребенка, его отношение к основным фигурам привязанности, а также на уровень стресса у замещающих родителей (Gobind, 2013; Boyle, 2015; Fossum et al., 2018). При этом негативный эффект наблюдался при контактах детей с биологическими родителями, жестоко обращавшимися с ними, тогда как положительный эффект отмечался при условии вовлеченности замещающих родителей во взаимодействие с биологическими (Boyle, 2015). Повышение такой вовлеченности наблюдалось при предварительной тренинговой подготовке и последующем сопровождении замещающих родителей (Sanchirico, Jablonka, 2000). 
Согласно данным литературы, решение о поддержании контакта должно приниматься индивидуально в каждом отдельном случае и не может распространяться на всех детей, воспитывающихся в замещающих семьях (Gobind, 2013). Кроме того, отмечается, что такие факторы, как особенности психического здоровья воспитанников, возраст их помещения в семью, качество семейной заботы, включая наличие поддержки со стороны замещающих родителей, оказывают значительно большее влияние на отношения приемных детей в замещающей семье, чем эпизоды контактов с биологическими родственниками (Ibid.).

Преждевременное прерывание воспитания в семье имеет множественные негативные последствия как для психологического функционирования детей в виде переживания чувства утраты, изоляции, потери самоидентичности, обесценивания отношений, ухудшения адаптации и в целом психической травматизации (Tobin, 2013; Капилина (Пичугина), Панюшева, 2015; LopezBrock, Morales, 2016), так и для замещающих родителей (Selwyn et al., 2014; Корзетова, 2016). Анализ исследований свидетельствует о том, что в системе сопровождения особое место должен занимать этап подготовки потенциальных родителей к приему ребенка, а программы должны быть ориентированы на стабилизацию эмоционального состояния и снижение уровня стресса у членов семьи, преодоление ими травматического опыта и утрат, обучение навыкам управления трудным поведением воспитанников (Maaskant, 2016; Mnisi, Botha, 2016). Существенный вклад в профилактику патологического процесса, развивающегося в семье перед принятием решения об отказе от продолжения воспитания ребенка, вносят своевременность и индивидуальная направленность предоставляемого сопровождения (Khoo, Skoog, 2014). Показано, что эффективность семейной заботы напрямую связана с характеристиками взаимодействия между замещающим родителем и приемным ребенком, а не с их индивидуальными особенностями (Brown, Bednar, 2006). Поэтому для специалистов сопровождения представляется важным передавать замещающим родителям такое понимание ребенка, в котором трудности его поведения рассматриваются как проявления эмоциональных и социальных проблем, потребностей в стабильности ближайшего окружения и формировании семейного «терапевтического» микросоциума (Harkin, Houston, 2016).

Согласно данным исследований, службы сопровождения детей и родителей в замещающих семьях должны не только констатировать факт высокой потребности семей в помощи с предложением общих мер по организации и реализации этапов сопровождения (Попова, 2012; Серебрякова, 2014; Захарова, 2015; Колпакова, 2015), но и целенаправленно использовать программы вмешательства, показавшие эффективность с точки зрения стабильности размещения детей в замещающих семьях. Такие программы направлены на улучшение физического и психического здоровья приемных детей в долгосрочной перспективе (Fisher et al., 2009; Hambrick et al., 2016; Icheku, Paris, 2018; Bergström et al., 2020) и должны включать сопровождение как процесса взаимодействия и формирования отношений приемного ребенка с родителя- 
ми в замещающей семье, так и общения его и замещающих родителей с биологической семьей при учете потребностей воспитанника.

\section{Заключение}

Настоящее исследование было посвящено выявлению, анализу, систематизации и обобщению научных данных, полученных при изучении причин, влияющих на отказ замещающих семей от продолжения воспитания приемных детей. Анализ российских и зарубежных исследований в этой области позволяет получить более отчетливое представление о факторах риска, повышающих вероятность преждевременного прерывания воспитания приемных детей в замещающих семьях. К таковым можно отнести особенности приемных детей, характеристики замещающих родителей и их семей, а также следствия возможных контактов воспитанников с биологической семьей. Вместе с тем только понимания факторов, влияющих на стабильность размещения приемных детей в замещающей семье, крайне недостаточно для того, чтобы выстраивать эффективную систему профилактики вторичных отказов. Значительно более существенную роль в сохранении детей в семье играют качество родительской заботы, которое напрямую связано с характеристиками взаимодействия ребенка и замещающего родителя, наличие у семьи разнообразной поддержки, своевременность и индивидуальная направленность сопровождения, предварительная тренинговая подготовка, ориентированная не только на предоставление информации, но и на работу с эмоциональным состоянием родителей и членов семьи, принимающей ребенка, помощь в преодолении травматического опыта и обучение навыкам взаимодействия, включая управление трудным поведением.

Полученные в работе результаты позволяют сделать следующие выводы:

1. Отказ от сохранения приемного ребенка в семье представляет собой сложное явление, на которое оказывают влияние разнообразные факторы, связанные с особенностями как детей, так и замещающих родителей, а также с влиянием биологической семьи на процессы, происходящие в замещающей семье.

2. Опыт отказа, переживаемый как приемным ребенком, так и замещающими родителями, имеет множественные негативные психологические последствия для обеих сторон, в том числе в виде переживания чувства утраты, изоляции, обесценивания отношений, психической травматизации.

3. Обеспечение проживания детей-сирот и детей, оставшихся без попечения биологических родителей, в стабильных и качественных условиях замещающей семьи предполагает повышение качества подготовки замещающих родителей, а также разработку и внедрение научно обоснованных профилактических программ сопровождения ребенка и замещающей семьи. 


\section{Литература}

Беспалова, Н. Н. (2019). Профилактика вторичного сиротства на примере деятельности ГКУ «Детский дом (смешанный) № 13» Ставропольского края. Мир науки, культуры, образования, 3(76), 220-221.

Бирюкова, С. С., Варламова, М. А., Синявская, О. В. (2014, 8-21 сентября). Сиротство в России. Демоскоп Weekly, 609-610. http://www.demoscope.ru/weekly/2014/0609/tema01.php

Захарова, Ж. А. (2015). Психолого-педагогическое сопровождение замещающей семьи, принявшей на воспитание ребенка из учреждения государственного попечения. Вестник КГУ им. Н.А. Некрасова, 21, 216-220.

Заяц, О. В., Кизим, В. В. (2014). Профилактика вторичного социального сиротства в России. Актуальные проблемы гуманитарных и естественных наук, 12(2), 256-259.

Капилина (Пичугина), М. В., Панюшева, Т. Д. (2015). Приемный ребенок: жизненный путь, помощь и поддержка. М.: Никея.

Колпакова, Н. В. (2015). Психолого-педагогическое сопровождение замещающих семей как условие благополучия приемных детей. Мир науки, культуры, образования, 3(52), 260-263.

Корзетова, Е. А. (2016). Профилактика вторичных отказов. Пути решения проблемы вторичного сиротства. Социальное обслуживание семей и детей:научно-методический сборник, 7, 172-177.

Куфтяк, Е. В. (2012). Защитное поведение возвращенных детей-сирот. Вестник Костромского государственного университета им. Н.А. Некрасова. Серия: Педагогика. Психология. Социальная работа. Ювенология. Социокинетика, 18(3), 209-212.

Лаврентьева, 3. И. (2017). Возврат детей из замещающих семей как социально-педагогический феномен. Известия Саратовского университета. Новая серия. Серия Акмеология образования. Психология развития, 6(3(23)), 278-282. https://doi.org/10.18500/2304-9790-2017-6-3-278-282

Леонова, Е. Е. (2017). Социально-педагогические проблемы возврата детей из замещающих семей. Известия Саратовского университета. Новая серия. Серия Акмеология образования. Психология развития, 6(3(23)), 283-286. https://doi.org/10.18500/2304-9790-2017-6-3-283-286

Леонова, Е. Е. (2018). Восстановление доверия к взрослым как одно из условий преодоления последствий возврата подростков из замещающих семей. Сибирский педагогический журнал, 4, 102-110. https://doi.org/10.15293/1813-4718.1804.12

Лёвушкин, А. Н., Данилова, И. С. (2014). «Вторичное сиротство» и меры реагирования органов государственной власти на отказ приемных родителей от ребенка. Власть, 8, 159-163.

Махнач, А. В. (2016). Диагностика жизнеспособности и ресурсности замещающих семей как условие профилактики отказов от приемных детей. Организационная психология и психология труда, 1(1), 228-256.

Махнач, А. В., Прихожан, А. М., Толстых, Н. Н. (2015). (ред.). Проблема сиротства в современной России: психологческий аспект. М.: Изд-во «Институт психологии РАН».

Министерство труда и социальной защиты Российской Федерации. (2016). Государственный доклад о положении детей и семей, имеющих детей, в Российской Федеращии. https://rosmintrud.ru/docs/mintrud/protection/474

Мухамедрахимов, Р. Ж. (1999). Мать и младенеи: психологическое взаимодействие. СПб.: Изд-во Санкт-Петербургского университета.

Осипова, И. И. (2008). Феномен вторичного сиротства в современной России. Вестник Вятского государственного университета, 4(4), 138-143. 
Павлова, Т. В. (2015). Теория и практика работы со вторичным отказом от детей в принимающих семьях. Ресурсный центр помощи приемным семьям с особыми детьми. http://www.detivokrug.org/spetsialistam/149-vy-rabotaete-s-prijomnoj-semjoj-s-osobym-rebjonkom/metodiki-raboty/868-teoriya-i-praktika-raboty-so-vtorichnym-otkazom-ot-detej-v-prinimayushchikh-semyakh

Плешкова, Н. Л., Мухамедрахимов, Р. Ж. (2008). Отношения привязанности у детей в семьях и домах ребенка. В кн. Р. Ж. Мухамедрахимов (ред.), Эмощии и отношения человека на ранних этапах развития (с. 220-240). СПб.: Изд-во Санкт-Петербургского университета.

Попова, И. Н. (2012). Актуальные проблемы профессионального сопровождения замещающей семейной заботы. Психология и педагогика: методика и проблемь практического применения, $26,107-111$.

Рамих, А. А. (2018). Феномен «вторичное сиротство» как одна из форм психологического насилия над ребенком. Социальная работа в области защить детей в России и Германии: современное состояние и перспективы развития: Сборник материалов Международной научно-практической конференции в рамках III Международного фестиваля науки (с. 48-53). М.: МГОУ.

Ремизова, Л. В. (2014). Несоциализированное расстройство поведения у подростка в приемной семье (клинический случай). Прикладные информационные аспекты медицинь, 17(1), 152-155.

Решетова, О. П. (2016). Комплексная технология профилактики вторичных возвратов детей из замещающих семей. В кн. Приемная семья в диалоге с социумом: потребности, ответственность, ресурсы: Сборник материалов: региональный опыт, интересные практики, рассказы приемных родителей. М.: БФ «Здесь и сейчас». http://www.detivokrug.org/spetsialistam/149vy-rabotaete-s-prijomnoj-semjoj-s-osobym-rebjonkom/metodiki-raboty/1003-kompleksnayatekhnologiya-profilaktiki-vtorichnykh-vozvratov-detej-iz-zameshchayushchikh-semej

Семенова, О. Е. (2015). Профилактика возвратов приемных детей из семей в учреждение. Из опыта работы консультативной службы специализированного дома ребенка № 9 для кандидатов в приемные родители. В кн. Особый ребенок в приемной семье и в учреждении: социализация, интеграция, общественное мнение: Сборник материалов: региональный опыт, интересные практики, рассказы приемных родителей. М.: БФ «Здесь и сейчас». http://www.detivokrug.org/spetsialistam/185-vy-rabotaete-v-sisteme/organizatsiya-raboty-po-semejnomu-ustrojstvu/793-profilaktika-vozvratov-priemnykh-detej-iz-semej-v-uchrezhdenie-iz-opyta-raboty-konsultativnoj-sluzhbyspetsializirovannogo-doma-rebenka-no9-dlya-kandidatov-v-priemnye-roditeli

Семья, Г. В., Зайцев, Г. О., Зайцева, Н. Г. (2009). Мониторинг положения детей-сирот и детей, оставшихся без попечения родителей, и развитие семейных форм их устройства в ЦФО в 2008 г. (третий ежегодный доклад). М.: ООО «Вариант».

Серебрякова, В. В. (2014). Основные этапы сопровождения замещающей семьи. Наука и образование: новое время, 2, 57-62.

Фещенко, М. (2015). Подростковый возраст как фактор риска возникновения угрозы возврата. Благотворительный фонд помощи детям-сиротам «Здесь и сейчас». http://www.hereandnow.ru/info/podrostkovyi-vozrast-kak-faktor-riska-vozniknoveniya-ugrozy-vozvrata

Цинченко, Г. М. (2014). Социальное сиротство как феномен современного детства. Вестник СПбГУ, 12(1), 207-213.

Цыганова, Т. (2015). Реабилитащия детей, переживщих вторичное сиротство, в учреждении и подготовка к жизни в замещающей семье. Благотворительный фонд помощи детям-сиротам «Здесь и сейчас». http://www.hereandnow.ru/info/reabilitatsiya-detei-perezhivshikh-vtorichnoe-sirotstvo-v-uchrezhdenii-i-podgotovka-k-zhizni-v-zameshchayushchei-seme 
Шулятьева, С. Б., Логинова, Е. А., Жерновкова, И. В., Калашникова, Е. В. (2016). Профилактика вторичного сиротства: разрешение трудных ситуаций, возникающих в замещающих семьях. Образование: традищи и инноващии: Материаль ХII международной научно-практической конференции (с. 370-372). Прага: WORLD PRESS s r.o.

Ссылки на зарубежные источники см. в разделе References.

\section{References}

Ainsworth, M. D. S., Blehar, M., Waters, E., \& Wall, S. (1978). Patterns of attachment: A psychological study of the Strange Situation. Erlbaum.

Andersson, G. (2001). The motives of foster parents, their family and work circumstances. British Journal of Social Work, 31(2), 235-248. https://doi.org/10.1093/bjsw/31.2.235

Baginsky, M., Gorin, S., \& Sands, C. (2017). The fostering system in England: Evidence review. Research report: Executive summary. King's College London and Quest Research and Evaluation Ltd. https://www.gov.uk/government/publications/the-fostering-system-in-england-review

Bergström, M., Cederblad, M., Hekansson, K., Jonsson, A. K., Munthe, C., Vinnerljung, B., Wirtberg, I., Östlund, P., \& Sundell, K. (2020). Interventions in foster family care: A systematic review. Research on Social Work Practice, 30(1), 3-18. https://doi.org/10.1177/1049731519832101

Bespalova, N. N. (2019). Profilaktika vtorichnogo sirotstva na primere deyatel'nosti GKU "Detskii dom (smeshannyj) № 13” Stavropol'skogo kraya [Prevention of secondary orphanhood: a case study of activities of "Children's home (mixed type) No. 13" in Stavropol Territory]. Mir Nauki, Kul'tury, Obrazovaniya, 3(76), 220-221.

Biryukova, S. S., Varlamova, M. A., \& Sinyavskaya, O. V. (2014, September 8-21). Sirotstvo v Rossii [Orphanhood in Russia]. Demoskop Weekly, 609-610. http://www.demoscope.ru/weekly/2014/ 0609/tema01.php

Bowlby, J. (1969). Attachment and loss: Vol. 1. Attachment. Basic Books.

Boyle, C. (2015). "What is the impact of birth family contact on children in adoption and long-term foster care?” A systematic review. Child E Family Social Work, 22(S1), 22-33. https://doi.org/10.1111/cfs.12236

Brown, J. D., \& Bednar, L. M. (2006). Foster parent perceptions of placement breakdown. Children and Youth Services Review, 28(12), 1497-1511. https://doi.org/10.1016/j.childyouth.2006.03.004

Coman, W., \& Devaney, J. (2011). Reflecting on outcomes for looked-after children: An ecological perspective. Child Care in Practice, 17, 37-53.

Crum, W. (2010). Foster parent parenting characteristics that lead to increased placement stability or disruption. Children and Youth Services Review, 32, 185-190. https://doi.org/10.1016/j.childyouth.2009.08.022

Egelund, T., \& Vitus, K. (2009). Breakdown of care: the case of Danish teenage placements. International Journal of Social Welfare, 18, 45-56.

Farmer, E., Lipscombe, J., \& Moyers, S. (2004). Fostering adolescents. Jessica Kingsley Publishers.

Feshchenko, M. (2015). Podrostkovyi vozrast kak faktor riska vozniknoveniya ugrozy vozvrata [Adolescence as a risk factor for the threat of return]. Blagotvoritel'nyi fond pomoshchi detyamsirotam "Zdes' i seichas". http://www.hereandnow.ru/info/podrostkovyi-vozrast-kak-faktorriska-vozniknoveniya-ugrozy-vozvrata 
Fisher, P. A., Chamberlain, P., \& Leve, L. D. (2009). Improving the lives of foster children through evidenced-based interventions. Vulnerable Children and Youth Studies, 4(2), 122-127. https://doi.org/10.1080/17450120902887368

Font, S., \& Sattler, K. (2018). Measurement and correlates of foster care placement moves. Children and Youth Services Review, 91, 248-258. https://doi.org/10.1016/j.childyouth.2018.06.019

Fossum, S., Vis, S. A., \& Holtan, A. (2018). Do frequency of visits with birth parents impact children's mental health and parental stress in stable foster care settings. Cogent Psychology, 5(1), Article 1429350. https://doi.org/10.1080/23311908.2018.1429350

Gobind, T. (2013). Birth family contact and placement outcomes for children in kinship and foster care [Master's thesis, University of Canterbury, New Zealand]. University of Canterbury Research Repository. https://ir.canterbury.ac.nz/handle/10092/8082

Hambrick, E. P., Oppenheim-Weller, S., N'zi, A. M., \& Taussig, H. N. (2016). Mental health interventions for children in foster care: A systematic review. Children and Youth Services Review, 70, 6577. https://doi.org/10.1016/j.childyouth.2016.09.002

Harkin, C., \& Houston, S. (2016). Reviewing the literature on the breakdown of foster care placements for young people: complexity and the social work task. Child Care in Practice, 22(2), 98-112. https://doi.org/10.1080/13575279.2015.1102124

Icheku, V., \& Paris, C. (2018). Evidence based interventions to improve fostering relationships. LAP LAMBERT Academic Publishing. https://pdfs.semanticscholar.org/6e34/ 47b82aa391bf801e7b4db9dcde2cf37dd3a8.pdf

Kapilina (Pichugina), M. V., \& Panyusheva, T. D. (2015). Priemnyi rebenok: zhiznennyi put', pomoshch' i podderzhka [A foster child: life path, help and support]. Moscow: Nikeya.

Khoo, E., \& Skoog, V. (2014). The road to placement breakdown: Foster parents' experiences of the events surrounding the unexpected ending of a child's placement in their care. Qualitative Social Work, 13(2), 255-269. https://doi.org/10.1177/1473325012474017

Kolpakova, N. V. (2015). Psikhologo-pedagogicheskoe soprovozhdenie zameshchayushchikh semei kak uslovie blagopoluchiya priemnykh detei [Psychological and pedagogical support of foster families as a condition of well-being of foster children]. Mir Nauki, Kul'tury, Obrazovaniya, 3(52), 260-263.

Konijn, C., Admiraal, S., Baart, J., Rooij, F., Stams, G., Colonnesi, C., Lindauer, R., \& Assink, M. (2019). Foster care placement instability: A meta-analytic review. Children and Youth Services Review, 96, 483-499. https://doi.org/10.1016/j.childyouth.2018.12.002

Korzetova, E. A. (2016). Profilaktika vtorichnykh otkazov. Puti resheniya problemy vtorichnogo sirotstva [Prevention of secondary refusals. Solutions to the problems of secondary orphanhood]. Sotsial'noe Obsluzhivanie Semei i Detei, 7, 172-177.

Kuftyak, E. V. (2012). Zashchitnoe povedenie vozvrashchennyh detej-sirot [Defensive behavior of returned orphaned children]. Vestnik Kostromskogo Gosudarstvennogo Universiteta im. N.A. Nekrasova. Seriya: Pedagogika. Psikhologiya. Sotsial'naya Rabota. Yuvenologiya. Sotsiokinetika, 18(3), 209-212.

Lavrentyeva, Z. I. (2017). Return of children from substitute families as a socio-pedagogical phenomenon. Izvestiya Saratovskogo Universiteta. Novaya seriya. Seriya Akmeologiya Obrazovaniya. Psikhologiya Razvitiya, 6(3(23)), 278-282. https://doi.org/10.18500/2304-9790-2017-6-3-278-282 (in Russian)

Leathers, S., Spielfogel, J., Geiger, J., Barnett, J., \& Voort, B. (2019). Placement disruption in foster care: Children's behavior, foster parent support, and parenting experiences. Child Abuse E Neglect, 91, 147-159. https://doi.org/10.1016/j.chiabu.2019.03.012 
Leonova, E. E. (2017). Socio-pedagogical problems of children returned from substitute families. Izvestiya Saratovskogo Universiteta. Novaya Seriya. Seriya Akmeologiya Obrazovaniya. Psikhologiya Razvitiya, 6(3(23)), 283-286. https://doi.org/10.18500/2304-9790-2017-6-3-283-286 (in Russian)

Leonova, E. E. (2018). Restoring trust in adults as a factor of overcoming consequences of teenagers returned from substitute families. Sibirskii Pedagogicheskii Zhurnal, 4, 102-110. https://doi.org/10.15293/1813-4718.1804.12 (in Russian)

Leve, L. D., Harold, G. T., Chamberlain, P., Landsverk, J. A., Fisher, P. A., \& Vostanis, P. (2012). Practitioner review: Children in foster care - vulnerabilities and evidence based interventions that promote resilience processes. Journal of Child Psychology and Psychiatry, 53, 1197-1211. https://doi.org/10.1111/j.1469-7610.2012.02594.x

Lopez-Brock, M. D., \& Morales, C. F. (2016). Social and psychological implications of placement instability among former foster youth [Master's thesis, California State University, San Bernardino School of Social Work]. Electronic Theses, Projects, and Dissertations. https://scholarworks.lib.csusb.edu/etd/378

Lyovushkin, A. N., \& Danilova, I. S. (2014). "Vtorichnoe sirotstvo" i mery reagirovaniya organov gosudarstvennoi vlasti na otkaz priemnykh roditelei ot rebenka ["Secondary orphanhood" and response of state authorities to foster parents' refusal of a child]. Vlast', 8, 159-163.

Maaskant, A. M. (2016). Placement breakdown in foster care: Reducing risks by a foster parent training program? [PhD thesis, Universiteit van Amsterdam]. UvA-DARE (Digital Academic Repository). https://hdl.handle.net/11245/1.539918

Makhnach, A. V. (2016). Resilience and resources' diagnostics of foster families as a condition for the prevention of renouncement of foster children. Organizatsionnaya Psikhologiya i Psikhologiya Truda, 1(1), 228-256. (in Russian)

Makhnach, A. V., Prikhozhan, A. M., \& Tolstykh, N. N. (2015). (Eds.). Problema sirotstva v sovremennoi Rossii: psikhologicheskij aspekt [The problem of orphanhood in modern Russia: a psychological aspect]. Moscow: Institute of Psychology of the RAS.

Ministerstvo truda i sotsialnoi zashchity Rossiiskoi Federatsii. (2016). Gosudarstvennyi doklad o polozhenii detei i semei, imeyushchikh detei, v Rossiiskoi Federatsii [State report on the situation of children and families with children in the Russian Federation]. https://rosmintrud.ru/docs/ mintrud/protection/474

Mnisi, R., \& Botha, P. (2016). Factors contributing to the breakdown of foster care placements: the perspectives of foster parents and adolescents. Social Work/Maatskaplike Werk, 52(2), 227-244. https://doi.org/10.15270/52-2-502

Moyers, S., Farmer, E., \& Lipscombe, J. (2006). Contact with family members and its impact on adolescents and their foster placements. British Journal of Social Work, 36, 541-599.

Muhamedrahimov, R. J. (1999). Mat' i mladenets: psikhologicheskoe vzaimodeistvie [Mother and infant: a psychological interaction]. Saint Petersburg: Saint-Petersburg University Press.

Muhamedrahimov, R. J., Agarkova, V. V., Vershnina, E., Palmov, O. I., Nikiforova, N. V., McCall, R. B., \& Groark, C. J. (2014). Behavior problems in children transferred from a socioemotionally depriving institution to St. Petersburg (Russian Federation) families. Infant Mental Health Journal, 35(2), 111-122.

Murray, L., Tarren-Sweeney, M., \& France, K. (2011). Foster carer perceptions of support and training in the context of high burden of care. Child and Family Social Work, 16(2), 149-158. 
Nelson, Ch. A., Fox, N. A., \& Zeanah, Ch. H. (2014). Romania's abandoned children: Deprivation, brain development, and the struggle for recovery. Harvard University Press.

Oosterman, M., Shuengel, C., Wim Slot, N., Bullens, R., \& Doreleijers, T. (2007). Disruptions in foster care: A review and meta-analysis. Children and Youth Services Review, 29, 53-76.

Osipova, I. I. (2008). Fenomen vtorichnogo sirotstva v sovremennoi Rossii [The phenomenon of secondary orphanhood in modern Russia]. Vestnik Vyatskogo Gosudarstvennogo Universiteta, 4(4), $138-143$.

Pavlova, T. V. (2015). Teoriya i praktika raboty so vtorichnym otkazom ot detei v prinimayushchikh sem'yakh [Theory and practice of working with secondary abandonment of children in host families]. Resursnyi tsentr pomoshchi priemnym sem'yam s osobymi det'mi. http://www.detivokrug.org/spetsialistam/149-vy-rabotaete-s-prijomnoj-semjoj-s-osobym-rebjonkom/metodiki-raboty/868-teoriya-i-praktika-raboty-so-vtorichnym-otkazom-ot-detej-vprinimayushchikh-semyakh

Pleshkova, N. L., \& Muhamedrahimov, R. J. (2008). Otnosheniya privyazannosti u detei v sem'yakh i domakh rebenka [Attachment in children in families and institutions]. In R. J. Muhamedrahimov (Ed.), Emotsii i otnosheniya cheloveka na rannikh etapakh razvitiya [Emotions and relationships at the early stages of development] (pp. 220-240). Saint Petersburg: Saint Petersburg University Press.

Popova, I. N. (2012). Aktual'nye problemy professional'nogo soprovozhdeniya zameshchayushchei semeinoi zaboty [Acute problems of professional support of substitute family care]. Psikhologiya $i$ Pedagogika: Metodika i Problemy Prakticheskogo Primeneniya, 26, 107-111.

Ramikh, A. A. (2018). Fenomen "vtorichnoe sirotstvo" kak odna iz form psihologicheskogo nasiliya nad rebenkom [The phenomenon of "secondary orphanhood" as a form of psychological abuse of a child.]. In Sotsial'naya rabota v oblasti zashchity detei v Rossii i Germanii: sovremennoe sostoyanie i perspektivy razvitiya: sbornik materialov Mezhdunarodnoi nauchno-prakticheskoi konferentsii v ramkakh III Mezhdunarodnogo festivalya nauki [Social work in the field of child protection in Russia and Germany: current state and prospects of development: Proceedings of the International Scientific and Practical Conference in the framework of the III International Festival of Science] (pp. 48-53). Moscow: MGOU.

Remizova, L. V. (2014). Nesotsializirovannoe rasstroistvo povedeniya u podrostka v priemnoi sem'e (klinicheskii sluchai) [A clinical case of unsocialized behavior disorder in a teenager, observed in a foster family]. Prikladnye Informatsionnye Aspekty Meditsiny, 17(1), 152-155.

Reshetova, O. P. (2016). Kompleksnaya tekhnologiya profilaktiki vtorichnykh vozvratov detei iz zameshchayushchikh semei [Complex technology for the prevention of secondary returns of children from foster families]. In Priemnaya sem'ya v dialoge s sotsiumom: potrebnosti, otvetstvennost', resursy: sbornik materialov: regional'nyi opyt, interesnye praktiki, rasskazy priemnykh roditelei [Foster family in dialogue with society: needs, responsibility, resources: Collection of materials: regional experience, interesting practices, stories of foster parents]. Moscow: BF “Zdes' i seichas". http://www.detivokrug.org/spetsialistam/149-vy-rabotaete-s-prijomnoj-semjoj-s-osobym-rebjonkom/metodiki-raboty/1003-kompleksnaya-tekhnologiya-profilaktiki-vtorichnykh-vozvratovdetej-iz-zameshchayushchikh-semej

Richardson, E., Grogan, C., Richardson, Sh., \& Small, Sh. (2018). Displacement, caregiving, and the ecological system of youth in foster care: a theoretical perspective. Journal of Family Social Work, 21(4-5), 348-364. https://doi.org/10.1080/10522158.2018.1469561 
Rutter, M., Beckett, C., Castle, J., Colvert, E., Kreppner, J., Mehta, M., Stevens, S., \& Sonuga-Barke, E. (2009). Effects of profound early institutional deprivation: An overview of findings from a UK longitudinal study of Romanian adoptees. In G. Wrobel \& B. Neil (Eds.), International advances in adoption research for practice (pp. 147-168). Wiley-Blackwell.

Sallnas, M., Vinnerlijung, B., \& Kyhle Westermark, P. (2004). Breakdown of teenage placements in Swedish foster and resident care. Child and Family Social Work, 9, 141-152.

Sanchirico, A., \& Jablonka, K. (2000). Keeping foster children connected to their biological parents: The impact of foster parent training and support. Child and Adolescent Social Work Journal, 17, 185-203. https://doi.org/10.1023/A:1007583813448

Santen, E. (2015). Factors associated with placement breakdown initiated by foster parents - empirical findings from Germany. Child and Family Social Work, 20(2), 191-201.

Selwyn, J., Wijedasa, D., \& Meakings, S. (2014). Beyond the Adoption Order: challenges, interventions and adoption disruption: Research report. University of Bristol, School for Policy Studies, Hadley Centre for Adoption and Foster Care Studies. https://www.gov.uk/government/publications/beyond-theadoption-order-challenges-intervention-disruption

Semenova, O. E. (2015). Profilaktika vozvratov priemnykh detei iz semei v uchrezhdenie. Iz opyta raboty konsul'tativnoi sluzhby spetsializirovannogo doma rebenka № 9 dlya kandidatov v priemnye roditeli [Prevention of the return of foster children from families to an institution. From the experience of counselling service in the Infant Orphanage No. 9 for candidates for foster parents]. In Osobyi rebenok v priemnoi sem'e iv uchrezhdenii: sotsializaciya, integratsiya, obshchestvennoe mnenie: sbornik materialov: regional'nyi opyt, interesnye praktiki, rasskazy priemnykh roditelei [A special child in a foster family and an institution: socialization, integration, public opinion: collection of materials: regional experience, interesting practices, stories of foster parents]. Moscow: BF "Zdes' i seichas". http://www.detivokrug.org/spetsialistam/185-vy-rabotaete-v-sisteme/organizatsiya-raboty-po-semejnomu-ustrojstvu/793-profilaktika-vozvratov-priemnykh-detej-iz-semejv-uchrezhdenie-iz-opyta-raboty-konsultativnoj-sluzhby-spetsializirovannogo-doma-rebenkano9-dlya-kandidatov-v-priemnye-roditeli

Sem'ya, G. V., Zaitsev, G. O., \& Zaitseva, N. G. (2009). Monitoring polozheniya detei-sirot i detei, ostavshikhsya bez popecheniya roditelei, i razvitie semeinykh form ikh ustroistva v CFO v 2008 (tretii ezhegodnyi doklad) [Monitoring the situation of orphans and children left without parental care and the development of family forms of their placement in the Central Federal District in 2008 (third annual report)]. Moscow: OOO "Variant".

Serebryakova, V. V. (2014). Osnovnye etapy soprovozhdeniya zameshchayushchej sem'i [The main stages of substitute family support]. Nauka i Obrazovanie: Novoe Vremya, 2, 57-62.

Shulyat'eva, S. B., Loginova, E. A., Zhernovkova, I. V., \& Kalashnikova, E. V. (2016). Profilaktika vtorichnogo sirotstva: razreshenie trudnykh situatsii, voznikayushchikh v zameshchayushchikh sem'yakh [Prevention of secondary orphanhood: the resolution of difficult situations that arise in adoptive families]. In Obrazovanie: traditsii i innovatsii: Materialy XII mezhdunarodnoi nauchno-prakticheskoi konferentsii [Education: Traditions and Innovations: Proceedings of the XII International Scientific and Practical Conference] (pp. 370-372). Prague, CZ: WORLD PRESS s r.o.

Sinclair, I., Wilson, K., \& Gibbs, I. (2005). Foster placements: Why they succeed and why they fail. Jessica Kingsley.

Stanley, N., Riordan, D., \& Alaszewski, H. (2005). The mental health of looked-after children: Matching response to need. Health and Social Care in the Community, 13, 239-248. 
Stern, D. N. (1985). The interpersonal world of the infant. A view from psychoanalysis and developmental psychology. Basic Books.

Thomas, N. (2005). Social work with young people in care: Looking after children in theory and practice. Palgrave Macmillan.

Tobin, S. (2013). Young people's experiences of foster care placement breakdown. [Master's thesis, Trinity College Dublin]. https://www.tcd.ie/swsp/assets/pdf/M.Sc.\%20in\%20Applied\%20Social\%20Research\%20Dissertations/Tobin,\%20Sinead\%20Marie.pdf

Tsinchenko, G. M. (2014). Social orphanage as a phenomenon of modern childhood. Vestnik SanktPeterburgskogo Universiteta. Seriya 12. Psikhologiya. Sotsiologiya. Pedagogika, 12(1), 207-213. (in Russian)

Tsyganova, T. (2015). Reabilitatsiya detei, perezhivshih vtorichnoe sirotstvo, v uchrezhdenii i podgotovka $k$ zhizni v zameshchayushchei sem'e [Institutional rehabilitation of children who have experienced secondary orphanhood and preparation for life in a foster family]. Blagotvoritel'nyi fond pomoshchi detyam-sirotam "Zdes' i seichas". http://www.hereandnow.ru/info/reabilitatsiyadetei-perezhivshikh-vtorichnoe-sirotstvo-v-uchrezhdenii-i-podgotovka-k-zhizni-vzameshchayushchei-seme

Vanderfaeillie, J., Goemans, A., Damen, H., Van Holen, F., \& Pijnenburg, H. (2018a). Foster care placement breakdown in the Netherlands and Flanders: Prevalence, precursors, and associated factors. Child E Family Social Work, 23(3), 337-345. https://doi.org/10.1111/cfs.12420

Vanderfaeillie, J., Van Holen, F., Carlier, E., \& Fransen, H. (2018b). Breakdown of foster care placements in Flanders: incidence and associated factors. European Child \& Adolescent Psychiatry, 27(2), 209-220. https://doi.org/10.1007/s00787-017-1034-7

Vorria, P., Papaligoura, Z., Dunn, J., van IJzendoorn, M. H., Steele, H., Kontopoulou, A., \& Sarafidou, Y. (2003). Early experiences and attachment relationships of Greek infants raised in residential group care. Journal of Child Psychology and Psychiatry, 44(8), 1208-1220. https://doi.org/10.1111/1469-7610.00202

Williams-Mbengue, N. (2016). The social and emotional well-being of children in foster care. Washington, National Conference of State Legislatures. https://www.ncsl.org/research/humanservices/the-social-and-emotional-well-being-of-children-in-foster-care.aspx

Zakharova, Zh. A. (2015). Psikhologo-pedagogicheskoe soprovozhdenie zameshchayushchei sem'i, prinyavshei na vospitanie rebenka iz uchrezhdeniya gosudarstvennogo popecheniya [Psychological and pedagogical support of a foster family, which accepted a child from a state care institution]. Vestnik Kostromskogo Gosudarstvennogo Universiteta im. N.A. Nekrasova, 21, 216-220.

Zayats, O. V., \& Kizim, V. V. (2014). Profilaktika vtorichnogo sotsial'nogo sirotstva v Rossii [Prevention of secondary social orphanhood in Russia]. Aktual'nye Problemy Gumanitarnykh $i$ Estestvennykh Nauk, 12(2), 256-259. 